\title{
The differences in the width of male and women maxillary sinus seen from panoramic radiography in tribe Students Minang Faculty of Dental Medicine, Baiturrahmah University
}

\author{
Resti Iswani, ${ }^{1 *}$ Rizki Wulandari, ${ }^{1}$ Firdaus, ${ }^{2}$ Hamdy Lisfrizal ${ }^{1}$
}

\section{Abstract}

Objective: The purpose of this study was to determine whether there is a difference in the width of the maxillary sinus between male and female students of the Minang ethnic group, Faculty of Dentistry, Baiturrahmah University, seen from panoramic radiographs.

Material and Methods: This study is an analytical study with a sample size of 50 respondents using purposive sampling method. The data analysis is displayed using the frequency distribution table and the significance level using the SPSS program with the independent t-test.
Results: The results showed that the mean value of the width of the right maxillary sinus in men was $35.06 \mathrm{~mm}$ (Cl 1.7381 \pm 6.4219$)$, while in women it was $30.98 \mathrm{~mm}$ (Cl $1.7378 \pm 6.4232)$. The mean value of the left maxillary sinus width in men was $35.38 \mathrm{~mm} \mathrm{(Cl} 2.6736 \pm$ 6.6464), while in women it was $30.72 \mathrm{~mm}$ ( $\mathrm{Cl} 2.6732 \pm 6.6469)$.

Conclusion: The conclusion of this study is that there is a significant difference between the width of the maxillary sinuses of men and women in Minang ethnic students, Faculty of Dentistry Baiturrahmah University with a $p$ value $<0.05$.
'Department of Radiology, Faculty of Dentistry, Baiturrahmah University, Padang, Indonesia

${ }^{2}$ Department of Oral Surgery, Faculty of Dentistry, Baiturrahmah University, Padang, Indonesia
*Correspondence to: Resti lswani, Department of Radiology, Faculty of Dentistry, Baiturrahmah University, Padang, Indonesia restyiswani@gmail.com

Received: 14 August 2020 Revised: 22 November 2020 Accepted: 19 December 2020 Available Online: 1 April 2021

Keywords: Gender, Maxillary sinus, Minang tribe

Cite this Article: Iswani R, Wulandari R, Firdaus, Lisfrizal H. 2021. The differences in the width of male and women maxillary sinus seen from panoramic radiography in tribe Students Minang Faculty of Dental Medicine, Baiturrahmah University. Journal of Dentomaxillofacial Science 6(1): 35-38. DOl: 10.15562/jdmfs.v6i1.1094

\section{Introduction}

Indonesia is a country geographically prone to natural disasters, such as landslides, earthquakes, volcanic eruptions, tsunamis and floods. ${ }^{1}$ Recent research in the West Sumatra region indicates that the Mentawai segment of the Megathrust is Sumatra likely to undergo a shift in the next few decades, as the energy accumulated is too large. This plate shift can trigger an earthquake that has the potential to cause severe damage to most cities in Sumatra and trigger a tsunami disaster. Therefore, the people in Padang City are $88 \%$ are Minang people who have a very high risk of becoming disaster victims.

There are three racial groups in the world, among others: Mongoloid, Negroid, and Caucasoid. Indonesia is included in the Mongoloid group. The Mongoloid race consists of the Detro Melayu and Proto Melayu sub-racial groups. These racial characteristics are related to anthropometry, namely in measuring the frame and body. The Minang tribe comes from the Mongoloid race, which has a characteristic type cranium: bone zygomaticus a prominent, width of the medium apertura nasalis and a slightly tapered lower edge, and a medium palate width.

Forensic identification is an effort made with the aim of helping investigators determine someone's identity. The identification process is carried out based on the Interpol criteria, namely primary identification and secondary identification. Primary identification consisted of fingerprint analysis, teeth analysis and DNA analysis. Secondary identification includes a description of the individual (tattoos, scars, gender, and jewelry), medical findings, clothing and other evidence found. ${ }^{2}$ Identification in Indonesian law is regulated in Law No.36 of 2009 Article 118 paragraph 1 concerning health, which states that an unrecognized corpse must be subjected to identification efforts. ${ }^{3}$

Individual identification can be done through several parameters, namely determining the approximate age, race and gender. ${ }^{4}$ However, not all forensic cases provide a complete skeleton due to postmortem damage. Generally the skull is more resistant to damage because it is made up of hard tissue. ${ }^{5}$ One of these is the maxillary sinus which is wide and high can be used to determine sex when the skeleton is incomplete. ${ }^{6}$

The maxillary sinuses are air spaces, located on the maxillary bones in various sizes and shapes. The process of formation of the maxillary sinuses is completed at about 20 years of age. The maxillary sinus tends to stabilize after the second decade of 
life. The lower part of the maxillary sinus lies adjacent to the alveolar bone, first molars, second molars and third molars and the roots of the canines. ${ }^{7}$

Gender identification based on maxillary sinus size can be done using CT-scan and panoramic radiography. CT-scans provide more accurate results, because they can provide a three- dimensional image. Panoramic radiographs are used to examine the maxillary sinuses to support the initial diagnosis. Panoramic radiographs are less expensive and have a smaller radiation dose than CT scans. Panoramic radiographs provide bilateral maxillary and mandibular views and maxillary sinus mesiodistally. ${ }^{8 \mathbb{}}$ So that the maxillary sinus size is considered to be able to identify sex through panoramic radiographs with digital sensors.

Using lateral cephalometric radiographs, showed that the mean maxillary sinus width in men was $36.11 \mathrm{~mm} \pm 4.53 \mathrm{~mm}$, while the mean maxillary sinus width in women was $32.12 \mathrm{~mm} \pm 3.95 \mathrm{~mm}$. The mean maxillary sinus height in men was $27.46 \mathrm{~mm}$ $\pm 3.39 \mathrm{~mm}$, while the mean height the maxillary sinus in women is $27.08 \mathrm{~mm} \pm 3.95 \mathrm{~mm}$. Research Vidya years 2013, using 3D CT-scan, all maxillary sinus sizes were well sized anterior posterior, the vertical dimension or width in males is greater than in females. The maximal anteroposterior size was $39.3 \pm 4.2 \mathrm{~mm}$ (male $40.7 \mathrm{~mm}$, female 37.4 ) $\mathrm{mm}$ ) and the maximum width is $32.6 \pm 6.5 \mathrm{~mm}$. 14 While Manja's study in 2015, the mean value of the maxillary sinus size of the left side was $25.86 \pm 2.98 \mathrm{~mm}$. The mean value of the right sided maxillary sinus size was $25.85 \pm 2.90 \mathrm{~mm}$. The mean value of the maxillary sinus size of the Batak students aged $20-30$ years was $25.86 \pm 2.93 \mathrm{~mm}$. Data analysis using independent $t$-test obtained $p>0.05$, this value indicates no significant difference.

For this reason, the authors write this paper in order to find out whether there is a difference in the width of the maxillary sinus between men and women in the Minang ethnic group of students of the Faculty of Dentistry Baiturrahmah University seen from panoramic radiographs.

\section{Material and Methods}

This type of research is quantitative with the research method used is analytical. The approach used is cross sectional. The population of this study were students of the Faculty of Dentistry, Baiturrahmah University aged 20-25 years, male and female, with two generations of ethnicity, totaling 172 people. The research sample used for this study were as follows :

Inclusion criteria; Willing to be a respondent (there is a statement letter), good panoramic photo results (maxillary sinus clearly visible, no superimposed, double exposure, elongation, foreshortening, horizontal overlapping, cone cutting), subjects did not have abnormalities tooth and skeletal development, subjects aged 20-25 years, minang tribe two generations and above.

Exclusion criteria; there was a fracture in the maxillary bone, there was a paranasal sinus abnormality.

Samples were obtained as many as 25 men and 25 women from 172 students of the Faculty of Dentistry at Baiturrahmah University who were two generations of Minang ethnic based on inclusion and exclusion criteria. Taking the subject using purposive sampling technique. Research was conducted in November 2018-January 2019 in the Radiology section of the Dental Hospital Baiturrahmah University, Padang, Sumatra West.

Procedure; Take panoramic photos and collect panoramic photos according to the inclusion criteria of samples from the Dental Hospital Baiturrahmah University, Padang, the results of panoramic photographs and each patient is given a different code, the radiographic results are observed and measured by the researcher by: Opening the software CliniView(software) version 10.1; Press search to open a panoramic photo to be observed; Press the image and create a copy to produce a panoramic view that is the same as the original; Press contrast brightness to clarify the presence of alveolar ridge; Press the drawing toolbar (line) to make a horizontal straight line at the most inferior border of the mandible (X line) and a straight line (Y line); Press measurement (length) and make a vertical straight line drawn perpendicular to the $\mathrm{X}$ line and the vertical distance is measured at three points, the vertical line or median line (p), the outer; Mesial maxillary sinus (Q), the outermost distal maxillary sinus (R), to get the height of the maxillary sinus left to right; Press measurement (length) to make a horizontal line drawn with an $\mathrm{X}$ line that has been made in the middle of the three lines (lines A, B, C); The measurement results will come out automatically. Take notes on the measurement results of the maxillary sinus. Analysis of data from the measurement of the maxillary sinus.

Analysis Using two different test mean independent (independent t-test) using Confidence Interval (CI) of $95 \%$ and obtained statistically significant with $\mathrm{p}<0.05$.

\section{Results}

The results of the maxillary sinus wide differences between men and women seen from panoramic radiographs figure 1 of Minang ethnic students at the Faculty of Dentistry, Baiturrahmah University. 


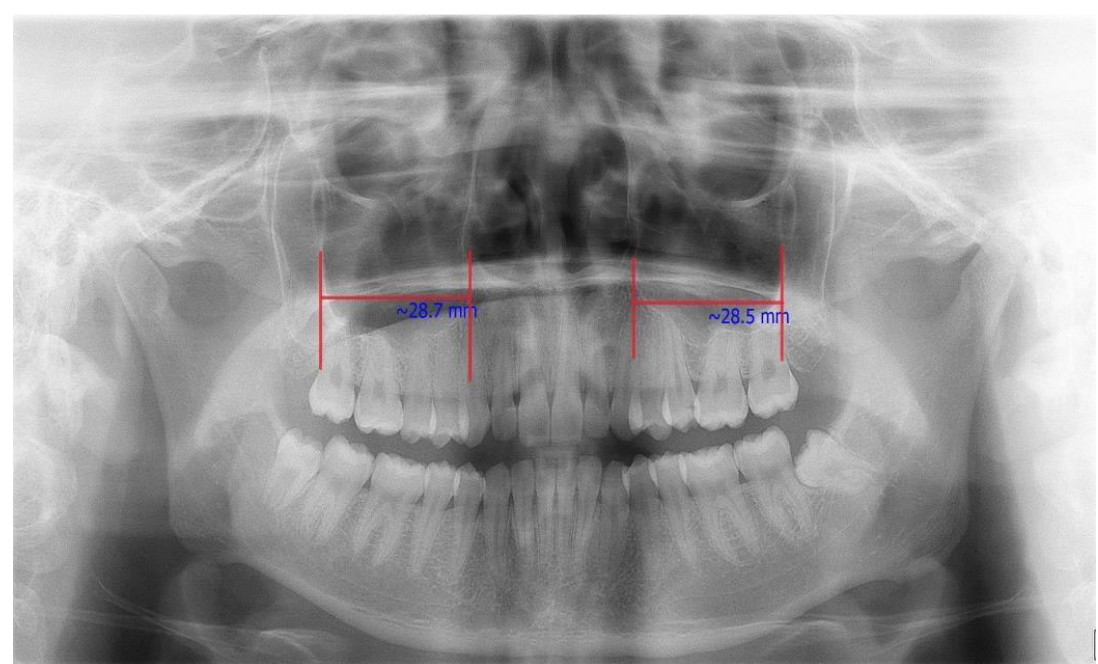

Figure 1 Maxillary sinus size analysis using panoramic radiography

Table 1 Measurement results of the average value of the right maxillary sinus width for men and women seen from panoramic radiographs

\begin{tabular}{lccc}
\hline Gender & $\begin{array}{c}\text { Mean Maxillary Sinus } \\
\text { Width Right (mm) }\end{array}$ & $\begin{array}{c}\text { P value } \\
\text { (Independent t test) }\end{array}$ & Cl 95\% \\
\hline Male & 35.06 & $\mathrm{P}=0.000$ & $1.7381 \pm 6.4219$ \\
Women & 30.98 & & $1.7378 \pm 6.4232$ \\
\hline
\end{tabular}

Table 2 Results of the average value of measurement left maxillary sinus width for men and women seen from panoramic radiographs

\begin{tabular}{lccc}
\hline Gender & $\begin{array}{c}\text { Mean Maxillary Sinus } \\
\text { Width Left }(\mathbf{m m})\end{array}$ & $\begin{array}{c}\text { P value } \\
\text { (Independent t test) }\end{array}$ & Cl 95\% \\
\hline Male & 35.38 & $\mathrm{P}=0.001$ & $2.6736 \pm 6.6464$ \\
Women & 30.72 & & $2.6732 \pm 6.649$ \\
\hline
\end{tabular}

Table 3 The measurement results of the average value of the right maxillary sinus width and left seen from radiography of panoramic

\begin{tabular}{lccc}
\hline Gender & $\begin{array}{c}\text { Mean Maxillary } \\
\text { Sinus Width }(\mathbf{m m})\end{array}$ & $\begin{array}{c}\text { P value } \\
\text { (Independent t test) }\end{array}$ & $\mathbf{C l ~ 9 5 \%}$ \\
\hline Male & 33.02 & $\mathrm{P}=0.976$ & $-1.76397 \pm 1.71197$ \\
Women & 33.05 & & $2.6732 \pm 6.649$ \\
\hline
\end{tabular}

Measurement of the average value of the width of the maxillary sinus in men and women:

Table 1 the average value of the width of the maxillary sinuses of the right and left men was greater than that of women. Based on statistical analysis using the independent $\mathrm{t}$-test, there was a significant difference between the maxillary sinus widths of men and women with a value of $\mathrm{p}=0.001$ (right) and $\mathrm{p}=0.000$ (left) table 2 .

Table 3 statistical analysis using the independent t-test, there was no significant difference between the width of the maxillary sinus left and right with a value of $p=0.976$.

\section{Discussion}

A study was conducted on 50 Minang ethnic student respondents at the Faculty of Dentistry, Baiturrahmah University by measuring the width of the maxillary sinuses using panoramic radiographs with the aim of knowing the differences in the size of the maxillary sinuses between men and women. The mean value of the right maxillary sinus width in men was $35.06 \mathrm{~mm}$ (CI $1.7381 \pm 6.4219$ ), while in women it was $30.98 \mathrm{~mm}$ (CI $1.7378 \pm 6.4232)$. And the mean value of the left maxillary sinus width in men was $35.38 \mathrm{~mm}$ (CI $2.6736 \pm 6.6464)$, while in women was $30.72 \mathrm{~mm}$ (CI $2.6732 \pm 6.6469)$.

There is a significant difference between the width of the maxillary sinus right and left in men and women, using the independent t-test shows a value of $p<0.05$. The average value of the right maxillary sinus in the Minang term was $33.02 \mathrm{~mm}$ (CI - 1.76397 \pm 1.71197 ), and the left was $33.05 \mathrm{~mm}$ (CI $-1.76413 \pm 1.71213$ ), on the test independent t-test showed no significant difference between right and left maxillary sinuses with a p value $>0.05$. Research. Using lateral cephalometric radiographs in the Batak tribe showed that the average maxillary sinus width in men was greater than in women. Vidya et al. ${ }^{11}$ using 3D CT-scan, all maxillary sinus sizes, both anteroposterior, vertical or wide dimensions in males were larger than females. Meanwhile, in the 2015 Manja study, there was no significant difference in the mean size of the maxillary sinus left and right of Batak students aged 20- 30 years.

The width of the maxillary sinus in males is greater than in females due to: male skulls are heavier, larger and coarser, whereas female skulls are lighter, smaller and smoother, and when viewed from the supraorbital, zygomatic, and bone bones Male occipital men are more prominent than women. ${ }^{11}$ The size of the maxillary sinus is also influenced by race, different races usually carry different morphological features, so there is a large number of biological variations in humans. These racial characteristics are also related to anthropometry, namely in measuring both the frame and body. In this study using samples from the Mongoloid race, which are characterized by the type of cranium which tends to have bone zygomaticus a prominent,width of the medium apertura nasalis and a slightly tapered lower edge, and medium width of the palate. ${ }^{2}$ This study uses panoramic radiography, panoramic radiography as a relatively inexpensive two-dimensional radiography, which has been proven to be used for gender identifica- 
tion based on the width of the maxillary sinus. Gender identification is an important first step in the forensicidentification process, because it can find a $50 \%$ probability of a match in the identification of an individual. Gender identification can be performed easily and with high accuracy using adult skulls. The difficulty of carrying out the identification and sex determination process makes it important to use denser bones that are often found intact, for example the maxillary sinus. ${ }^{12,15}$

If the skull is fully encountered in criminal cases and natural disasters, the sex can be determined with $100 \%$ accuracy. ${ }^{13}$ In the case of a natural disaster and a criminal case, where another bone is destroyed in the skull but the maxillary sinus cavity is good, the width of the maxillary sinus can be used to analyze the sex quickly. ${ }^{14}$

Another relevant finding of this study is that it is possible to determine sex even if the skull is fragmented as long as there is one maxillary sinus, According to our findings, panoramic radiographs can be very useful. However, there are some limitations to use them in the forensic area, such as lack of equipment in most forensic laboratories, and the difficulty to put the remains in a static or sitting position, due to rigor mortis. It is also noteworthy, as is often the case, that radiographs are not filed, processed or fixed, which limits their application. ${ }^{16-18}$

\section{Conclusion}

conclusion of this study is that there is a difference in the width of the maxillary sinuses between men and women seen from panoramic radiographs in Minang ethnic students at the Faculty of Dentistry, Baiturrahmah University aged 20-25 years, with a larger male maxillary sinus width. than women.

\section{Acknowledgment}

We would like to appreciate the Department of Radiology, Faculty of Dentistry, Baiturrahmah University for their support to facilitate this study.

\section{Conflict of Interest}

The authors report no conflict of interest.

\section{References}

1. Apriyono DK. Dental age determination method in victim identification process. CDK 2016;43: 4- 71. (In Indonesia)

2. Manja CD, Xiang LY. Analysis of the size of the maxillary sinus using panoramic radiography on students of the Batak tribe aged 20-30 years at the Faculty of Dentistry, Universitas Sumatera Utara. Dentika 2015;18: 94-101. (In Indonesia)

3. Uuroge A, Patil BA. Sexual dimorphism of maxillary sinus: a morphometric analysis using cone beam computed tomography. J Clin Diag Res 2017;11: 67- 70.

4. Tambawala SS, Karjodkar FR, Sansare K, et al. Sexual dimorphism of maxillary sinus using cone beam computed tomography. Egyp J Forensic Sci 2016;6: 95- 120.

5. Atmaji M, Yuni M, Atmadja DS. Lip examination method for individual identification. J PDGI 2013;62: 64-70. (In Indonesia)

6. Khantem V, Guttikonda S, Yeluri, et al. Sex determation using maxillary sinus. J Forensic Dent Sci 2015;7: 136- 167.

7. Bangi BB, Ginjupally U, Nadendla LK, et al. 3D evaluation of maxillary sinus using computed tomography: a sexual dimorphic study. Hindawi 2017;17: 14.

8. Teke HY, Duran S, Canturk N, et al. Determination of gender by measuring the size of the maxillary sinuses in computerized tomography scans. Surg Radiol Anat 2007;166:42- 84 .

9. Tambawala SS, Karjodkar FR, Sansare K, et al. Sexual dimorphism of maxillary sinus using cone beam computed tomography. Egyp J Forensic Sci 2016;6: 95- 120.

10. Kambylafkas P, Murdock E, Gilda E, et al. Validity of panoramic radiographs for measuring mandibular asymmetry. Angle Orthod 2005;76: 293- 388.

11. Vidya CS, Shamasundar NM, Manjunatha B, et al. Evaluation of size and volume of maxillary sinus to determine gender by 3D computerized tomography scan method using dry skulls of South Indian Origin. IJCRR 2013;5: 89- 97 .

12. Kunigal SP, Gowda C, Kokila G, et al. Gender determination using maxillary sinus. Int J Oral Care Res 2017;5: 19- 22.

13. Putri RD, Imanto M, Irianto GM. Gender identification based on Cone Beam Computed Tomography (CBCT). UJLS 2018;7: 232- 237. (In Indonesia)

14. Khaitan T, dkk. 2017. Cephalometric Analysis for Gender Determination using Maxillary Sinus Index. Int J Dent 2017;2017: 1- 4 .

15. Sidhu R, Chandra S, Devi P, et al. Forensic importance of maxillary sinus in gender determination. European J Gen Dent 2014;3: 53- 56.

16. Queiroz, Terada ASSD, Dezem TU, de-Araújo LG, et al. Sex determination of adult human maxillary sinuses on panoramic radiographs. Acta stomatol Croat 2016;50: 215- 221.

17. Malina-Altzinger J, Damerau G, Grätz KW, et al. Evaluation of the maxillary sinus in panoramic radiography-a comparative study. Int J Implant Dent 2015;1: 17.

18. Yunus B, Amalia R. Detecting osteoporosis in elderly women with panoramic radiography technique. J Dentomaxillofac Sci 2016;1: 155-157.

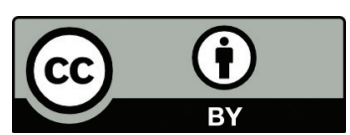

This work is licensed under a Creative Commons Attribution 